\title{
Blockade of receptor for advanced glycation end product attenuates pulmonary reperfusion injury in mice
}

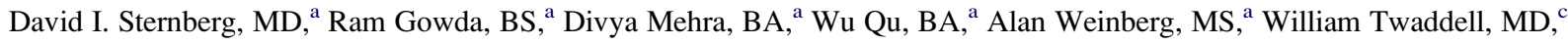 \\ Joydeep Sarkar, BS, ${ }^{a}$ Allison Wallace, $\mathrm{PhD},{ }^{\mathrm{b}}$ Barry Hudson, $\mathrm{PhD},{ }^{\mathrm{a}}$ Frank D’Ovidio, MD, PhD, ${ }^{\mathrm{a}}$ Selim Arcasoy, MD, \\ Ravichandran Ramasamy, PhD, ${ }^{a}$ Jeanine D'Armiento, MD, PhD, ${ }^{b}$ Ann Marie Schmidt, MD, ${ }^{a}$ and Joshua R. Sonett, MD
}

\begin{abstract}
Objective: The receptor for advanced glycation end products (RAGE) is expressed at high levels in the lung, particularly in type 1 alveolar cells, and has been shown to amplify injury triggered by acute stress. Previous studies suggest serum concentrations of soluble RAGE increase during pulmonary reperfusion injury after transplantation. RAGE blockade has been shown to suppress hepatic and cardiac ischemia and reperfusion injury in mice. Thus we tested the hypothesis that RAGE mediates tissue-injury mechanisms in ischemia and reperfusion injury in the lung.
\end{abstract}

\begin{abstract}
Methods: C57BL/6 mice were subjected to 30 minutes of pulmonary ischemia by clamping the left hilum, followed by 60 minutes of reperfusion. Lung function was assessed by means of blood gas analysis, and capillary leak was assessed by injecting fluorescein isothiocyanate-labeled albumin and comparing fluorescence in bronchial lavage fluid with that in serum. Histologic analysis of the lung was performed by a pathologist naive to the experimental conditions.
\end{abstract}

Results: In animals subjected to RAGE blockade, significant increases in $\mathrm{Po}_{2}(108$ vs $73 \mathrm{~mm} \mathrm{Hg}, P=.0094)$ and more than 3-fold decrease in capillary leak Relative Fluorescent Units (RFU, 6.12 vs $1.75 ; P=.001$ ) were observed. Histologic examination revealed significant injury reduction in soluble RAGE-treated animals versus control animals. RAGE knockout mice exhibited a protected phenotype when exposed to pulmonary ischemia and reperfusion. Additionally, interleukin 8 production and nuclear factor $\kappa \mathrm{B}$ activation were increased in control mice.

Conclusion: Abrogation of RAGE signaling attenuates pulmonary ischemia and reperfusion injury. This study suggests that RAGE might play a central role in pulmonary reperfusion injury and in transplantation and that blockade of RAGE might offer a potential target to abrogate pulmonary reperfusion injury in clinical transplantation.

Primary graft dysfunction (PGD) represents a significant source of postoperative morbidity after lung transplantation. ${ }^{1}$ It is the most common cause of early death after transplantation and, when diagnosed in severe forms, strongly correlates with increased duration of mechanical ventilation, as well as both intensive care unit and hospital lengths of stay. ${ }^{2-4}$ Patients who have severe PGD are more likely to have diminished forced expiratory volume in 1 second values and functional capacity and reduced overall rejection-free and total survival. ${ }^{5,6}$ Strong evidence suggests a direct relationship between pulmonary ischemia and reperfusion injury (IR) and PGD. ${ }^{3,7-12}$ Therefore pathways that

From the Lung Transplant Program, Department of Surgery, ${ }^{\mathrm{a}}$ Medicine, ${ }^{\mathrm{b}}$ and Patholo$\mathrm{gy},{ }^{\mathrm{c}}$ Columbia University College of Physicians and Surgeons, New York, NY.

This work was supported by grants from the National Institutes of Health (NIH5-T32 HL007854) and the Department of Surgery at Columbia University.

Received for publication March 13, 2008; revisions received May 9, 2008; accepted for publication May 26, 2008.

Address for reprint: Joshua R. Sonett, MD, General Thoracic Surgery, Columbia University College of Physicians and Surgeons, 622 West 168th St, PH-14 Room 104,

New York, NY 10032 (E-mail: js2106@columbia.edu).

J Thorac Cardiovasc Surg 2008;136:1576-85

0022-5223/ $\$ 34.00$

Copyright $\odot 2008$ by The American Association for Thoracic Surgery doi:10.1016/j.jtcvs.2008.05.032 play key regulatory roles in the propagation of inflammatory signals are putative targets of therapeutic interest.

The receptor for advanced glycation end products (RAGE) is both a marker of type 1 alveolar epithelial cell injury and a key early regulator of inflammation. ${ }^{13-15}$ RAGE is a multiligand, immunoglobulin-type transmembrane receptor. Under basal conditions, RAGE is expressed at low levels on a range of cell types but at much higher levels on the basolateral surface of type 1 alveolar epithelial cells. ${ }^{16-19}$ RAGE plays critical regulatory roles early in inflammatory signaling cascades that lead to endothelial dysfunction, capillary permeability, and vascular inflammation. Recent work has elucidated a possible link between RAGE and pulmonary IR. Human lungs with diminished airway fluid clearance are reported to have increased perfusate levels of soluble RAGE (sRAGE) on an ex vivo preservation circuit. ${ }^{20}$ Serum and lavage concentrations of sRAGE are increased during acid and lipopolysaccharide-induced lung injury in the rat. ${ }^{13}$ Additionally, lung transplant recipients with higher serum concentrations of sRAGE are more likely to have increased duration of mechanical ventilation and length of stay in the intensive care unit. ${ }^{13,21}$

However, little is known about the status of the RAGE signaling axis, its role, and its overall importance in 


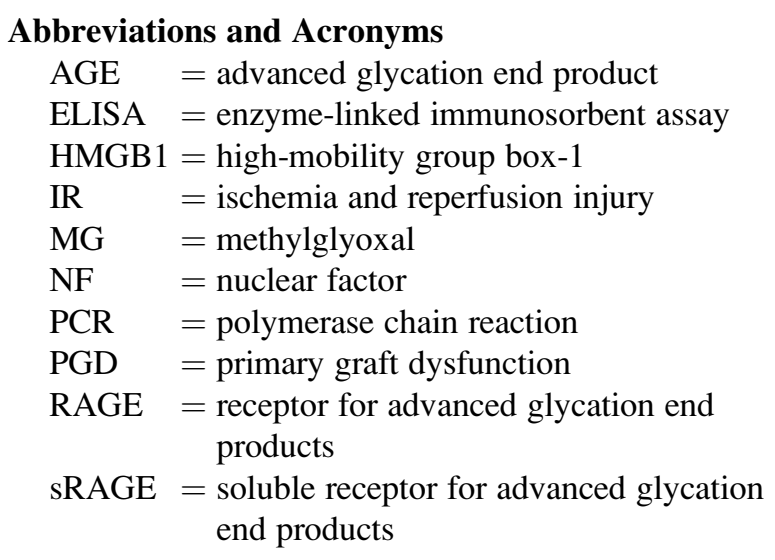

pulmonary IR. We therefore hypothesized that the RAGE pathway could have functional importance in this system. In this article we report our efforts to characterize the biology of the RAGE axis in a murine model of pulmonary ischemia and reperfusion and to determine its importance by antagonizing RAGE signaling and by analysis of RAGEdeficient mice.

\section{MATERIALS AND METHODS Animal Model}

Approximately 8- to 10-week-old C57BL6J male mice (Jackson Labs, Bar Harbor, Me) were divided into 4 groups: group 1, sham-treated group (negative control); group 2, vehicle saline-treated group (positive control); group 3, soluble RAGE-treated group (experimental group); and group 4, RAGE-null group. Group 1 sham animals underwent tracheostomy and bilateral thoracotomy but no ischemia or reperfusion. After thoracotomy, blood gas, lavage, serum, and tissue samples were obtained as the animal was killed. Group 2 (vehicle saline-injected positive control), group 3 (sRAGE-treated experimental group), and group 4 (RAGE-null group) animals underwent ischemia and reperfusion, as described below. Only group 3 animals received a preoperative injection of sRAGE. Group 2 (vehicle saline) and group 4 (RAGE null) animals underwent preoperative injection of vehicle saline.

sRAGE is a ligand decoy that traps putative molecules with a suitable epitope, such as members of the advanced glycation end product (AGE) family, and prevents interaction with the receptor, thus blocking RAGE signaling. sRAGE was prepared in a baculovirus expression system with Sf9 cells (Clontech, Palo Alto, Calif). The final material was purified to homogeneity and devoid of lipopolysaccharide, as previously described. ${ }^{22}$ RAGE-null mice were used for functional studies, including blood gas and capillary leak analysis. RAGE-null mice were backcrossed onto the C57Bl/6 background and exhibit normal reproductive capacity, physical fitness, and overall phenotype under nominal conditions but attenuated RAGE signaling when vascular inflammation is induced. ${ }^{23}$

One hour before the operation, the indicated animals received an intraperitoneal injection of $100 \mu \mathrm{g}$ of sRAGE in $0.1 \mathrm{~mL}$ of PBS or an equivalent volume of vehicle saline. Approximately 15 minutes before incision, each animal received $20 \mathrm{U}$ of subcutaneous heparin in $1 \mathrm{~mL}$ of PBS. Induction of anesthesia was achieved with buprenorphine $(0.05 \mathrm{mg} / \mathrm{kg})$ and $3 \%$ isoflurane delivered through a nose cone and maintained with $1 \%$ to $2.5 \%$ isoflurane and verified by means of tail pinch every 15 minutes. After shaving and prepping each animal with ethyl alcohol, a tracheostomy was performed, and each animal was placed on a Harvard Mouse Ventilator
(Harvard Biosciences, Holliston, Mass) through a 20-gauge angiocatheter (respiratory rate, 120 beats/min; fraction of inspired oxygen, 0.21 ; tidal volume, $0.5 \mathrm{~mL}$ ). Bilateral anterolateral thoracotomies were performed through the fourth intercostal space, and the chest wall was retracted with 4-0 silk stay sutures. The left pulmonary hilum was then crossclamped, and the tidal volume was reduced to $0.25 \mathrm{~mL}$ for a 30 -minute period. After the period of warm ischemia elapsed, the clamp was removed, ventilation with $0.5 \mathrm{~mL} /$ breath resumed, and an additional $1 \mathrm{~mL}$ of warmed PBS was delivered into the peritoneal cavity immediately and then every 60 minutes. After a 60- or 120-minute period of reperfusion, terminal phlebotomy of arterial blood from the left ventricle was performed for immediate analysis with the iSTAT blood gas analyzer (Abbott, East Windsor, NJ). The periods of ischemia and reperfusion were sometimes extended to suit experimental conditions or to confirm experimental findings. For example, this was done for histologic analyses in which more significant injury was needed. The entire left lung was then either flash-frozen in liquid nitrogen for biochemical analysis or insufflated with $20 \mathrm{~cm}$ of column pressure and fixed with $10 \%$ formaldehyde for histologic analysis.

\section{Capillary Leak}

Pulmonary edema is assessed by measuring leak of fluorescein isothiocyanate-labeled albumin into the lungs normalized against fluorescent activity in serum. Briefly, $0.15 \mathrm{mg}$ of fluorescein isothiocyanate-labeled albumin was injected into the tail vein 1 hour before the operation. After blood gas analysis, $0.5 \mathrm{~mL}$ of blood was withdrawn from the left ventricle. Both lungs were lavaged with $2 \mathrm{~mL}$ of PBS in 1-mL aliquots. Fluorescent activity of lavage fluid is normalized against diluted serum from each animal with a Bio-Rad Fluorimeter (Bio-Rad, Hercules Calif).

\section{Real-time Polymerase Chain Reaction (RAGE and Interleukin 8)}

Total RNA from $30 \mathrm{mg}$ of lung tissue was extracted with the Qiagen RNeasy Mini Kit (Qiagen, Inc, Valencia, Calif), according to the manufacturer's protocol. Reverse transcription was performed with the use of the High-Capacity cDNA Archive Kit (Applied Biosystems, Foster City, Calif). The reactions were carried out in a volume of $100 \mu \mathrm{L}$ containing approximately $15 \mu \mathrm{g}$ of RNA. The resulting cDNA was used as a template in the subsequent polymerase chain reaction (PCR). Expression levels for RAGE and interleukin 8 were quantified by means of real-time PCR, which was performed with the ABI Prism 7900HT Sequence Detection System (Applied Biosystems). The reactions were performed in a total volume of $20 \mu \mathrm{L}$ containing $1 \mu \mathrm{L}$ of the prepared cDNA template, $10 \mu \mathrm{L}$ of $2 \times$ Taqman Universal Master Mix (Applied Biosystems), and $1 \mu \mathrm{L}$ of $20 \times$ solution containing specific primers and probe. Each sample was run in triplicate. $\beta$-Actin was used as the housekeeping gene. The data were quantified by using the comparative $\mathrm{C} \tau$ method that reported the expressions relative to 3 sham samples included as housekeeping controls in each real-time PCR experiment.

\section{Western Blotting (RAGE, S100, and High-mobility Group Box-1)}

Lung samples were homogenized in equal volumes of cell lysis buffer (Cell Signaling, Danvers, Mass) on ice. After 3 cycles of sonication and centrifugation, the cell lysate was separated on a $10 \%$ acrylamide gel at $100 \mathrm{~V}$ and transferred to a nitrocellulose membrane in standard fashion. The membranes was then washed, blocked $(5 \%$ bovine serum albumin or milk, Tris-buffered $0.1 \%$ triton containing saline solution) and then incubated with either goat anti-mouse RAGE, rabbit anti-mouse S100 (Abcam, Cambridge, Mass), or rabbit anti-mouse high-mobility group box-1 (HMGB1) IgGs (BD PharMingen, Franklin Lakes, NJ) per the manufacturer's protocol. The membranes were washed again, labeled with horseradish peroxidase-labeled secondary antibody in blocking solution, developed in a chemiluminescent detection kit (Pierce, Rockford, Ill), and exposed on Kodak film (Rochester, NY). 


\begin{abstract}
Histology
For histologic analysis, all animals underwent an extended 60-minute period of warm ischemia, followed by an extended 120 minutes of reperfusion. This was done to amplify the degree of injury to suit the experimental conditions needed for histologic analyses. The animals were closely monitored, volume resuscitated every 60 minutes with $1 \mathrm{~mL}$ of warmed intraperitoneal saline, and censored from the study if premature cardiac arrest was encountered. After the 120-minute reperfusion period was complete, the lungs were excised, insufflated with $20 \mathrm{~cm}$ of column pressure of $10 \%$ formaldehyde, and fixed. After routine histologic processing in paraffin blocks, hematoxylin and eosin-stained sections were prepared and then scored by a blinded pathologist in 4 categories on a scale of 0 (no injury) to 4 (most severe injury): capillary congestion, hemorrhage, edema, and inflammation. After scoring was complete, the total numeric score was tabulated by summing all categories for each specimen, and the scores were then tested for significance by means of analysis of variance.
\end{abstract}

\section{Methylglyoxal}

Methylglyoxal (MG) was measured in the neutralized perchloric acid extracts of hearts by means of high-performance liquid chromatographic methods, according to previously published procedures. ${ }^{24,25}$

\section{Nuclear Factor $\kappa$ B and KC Enzyme-linked Immunosorbent Assay}

Nuclear protein was extracted from $40 \mathrm{mg}$ of lung tissue by using the Pierce NE-PER Nuclear and Cytoplasmic Extraction Reagents (Pierce Biotechnology). Nuclear factor (NF) $\kappa$ B activity was then determined in the nuclear protein by using the TransAM NF-kB enzyme-linked immunosorbent assay (ELISA) kit (Active Motif, Carlsbad, Calif), according to the manufacturer's protocol, with approximately $12 \mu \mathrm{g}$ of nuclear extract per well.

The concentration of mouse $\mathrm{KC}$ was determined in the protein samples by using the Quantikine Mouse KC kit (R\&D Systems, Minneapolis, Minn), according to the manufacturer's protocol. Approximately $40 \mu \mathrm{g}$ of total protein, prepared as directed by manufacturer protocol, was used per well. Both the NF- $\kappa$ B and KC ELISA kits were then scored on a Tecan Sunrise Plate Spectrophotometer (Tecan Co, Durham, NC).

\section{Statistical Methods}

In all cases the mean \pm standard error of the mean is shown. A 1-way analysis of variance was performed to analyze the results of all the experiments. If the $\mathrm{F}$ test resulted in a $P$ value of less than .05 , multiple comparisons were made by means of Tukey's pairwise testing, which conserves the overall type I error of .05. All data were analyzed with SAS system software (SAS Institute, Inc, Cary, NC).

\section{Ethical Guidelines}

All animals were housed, cared for, and treated in compliance with guidelines stipulated in the "Guide for the care and use of laboratory animals" and by the Institutional Animal Care and Use Committee, which approved and supervised this project. Funding agencies did not participate in data analysis or manuscript preparation.

\section{RESULTS}

\section{RAGE and Its Ligands in Pulmonary IR}

Expression of RAGE mRNA transcripts in lung tissue was assessed through real-time PCR after 30 minutes of ischemia and 60 minutes of reperfusion (Figure 1, A). Compared with sham-treated animals, an approximately $45 \%$ reduction in RAGE transcripts was observed in animals undergoing IR in the presence of vehicle $(P=.03)$, and an approximately $64 \%$ reduction in sRAGE-treated animals was seen compared with that seen in sham-treated animals $(P=.001)$. In parallel with these changes in RAGE transcripts, expression of RAGE protein, as determined after 30 minutes of ischemia and 60 minutes of reperfusion through Western blot analysis, revealed an approximately $27 \%$ reduction of RAGE protein in vehicle-treated animals $(P=.02)$ and an approximately $52 \%$ reduction in levels in sRAGE-treated animals after reperfusion compared with that seen in the sham-treated group $(P=.0001$; Figure 1 , $B$ and $C$ ). Trends observed between the sRAGE- and vehicle-treated groups that underwent surgical intervention did not reach statistical significance at the transcript $(P=.19)$ or protein $(P=.31)$ level.

To further assess the status of the RAGE axis, we tested the levels of the RAGE ligands. We first analyzed the AGE axis and focused on measurement of MG, a key preAGE and a highly cytotoxic $\alpha$-oxoaldehyde, the production of which is enhanced by hyperglycemia, inflammatory injury, and severe oxidative stress (Figure $1, D$ ). ${ }^{26} \mathrm{MG}$ is highly reactive with proteins and leads to the formation of multiple AGEs, which stimulate and upregulate the RAGE pathway. ${ }^{27,28}$ We measured MG levels in the lung tissue both after 30 minutes of ischemia and again after 60 minutes of reperfusion. MG levels were significantly increased in lung homogenates of control vehicle-treated animals undergoing IR compared with those seen in SRAGE-treated animals or sham-treated animals after ischemia (11.6 vs 3.6 $\mu \mathrm{g} / \mathrm{mL}, P=.04)$. However, no differences in MG levels were seen after reperfusion (data not shown).

Members of the S100/calgranulin proteins are intracellular calcium-binding proteins that are released by cells, such as stimulated macrophages, leukocytes, and lymphocytes, where they can bind RAGE, inducing RAGE signaling in an autocrine or paracrine manner. ${ }^{29}$ Increased levels of neutrophil-derived S100 have also been detected in pulmonary lavage fluid and lung parenchyma during acute lung injury. ${ }^{30}$ Amphoterin/HMGB1 is an intracellular DNA binding protein that is secreted by stimulated cells, such as macrophages, and also binds and upregulates the RAGE axis. ${ }^{31}$ We therefore measured both S100 (Figure 1, $E$ and $F$ ) and HMGB1 (Figure 1, $G$ and $H$ ) protein levels by means of Western blotting after 30 minutes of ischemia and 60 minutes of reperfusion injury. Compared with sham animals, there were no significant differences in levels of S100 or HMGB1 in vehicle- or sRAGE-treated mice $(P>.5)$.

\section{Functional Studies}

To test the potential effect of RAGE blockade on the functional capacity of the lungs, we used multiple methodologies. First, blood oxygen concentration was determined by means of routine arterial blood gas analysis performed on left ventricular blood immediately after reperfusion. Animals undergoing sham operations displayed a mean $\mathrm{PO}_{2}$ of 

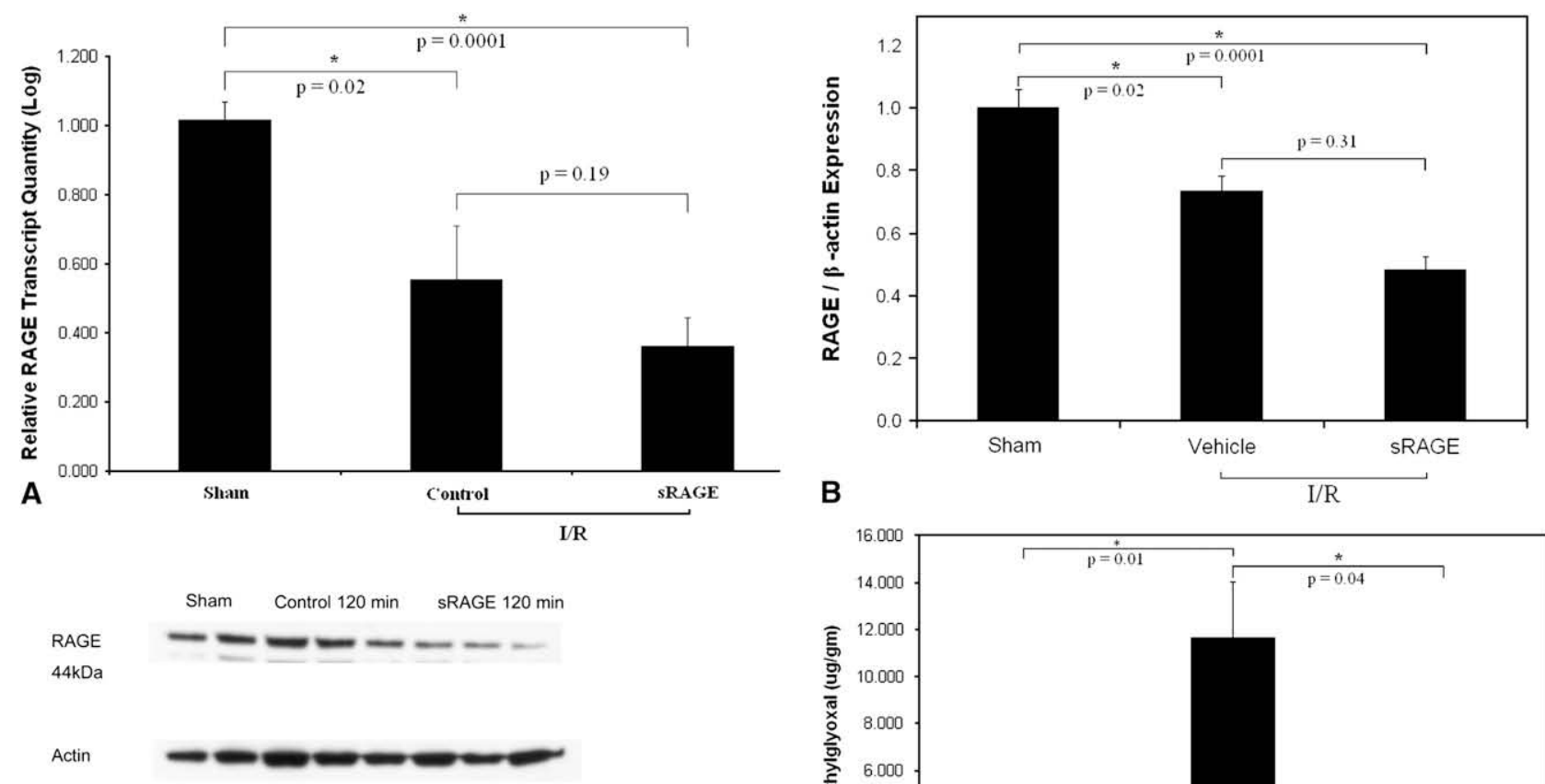

C
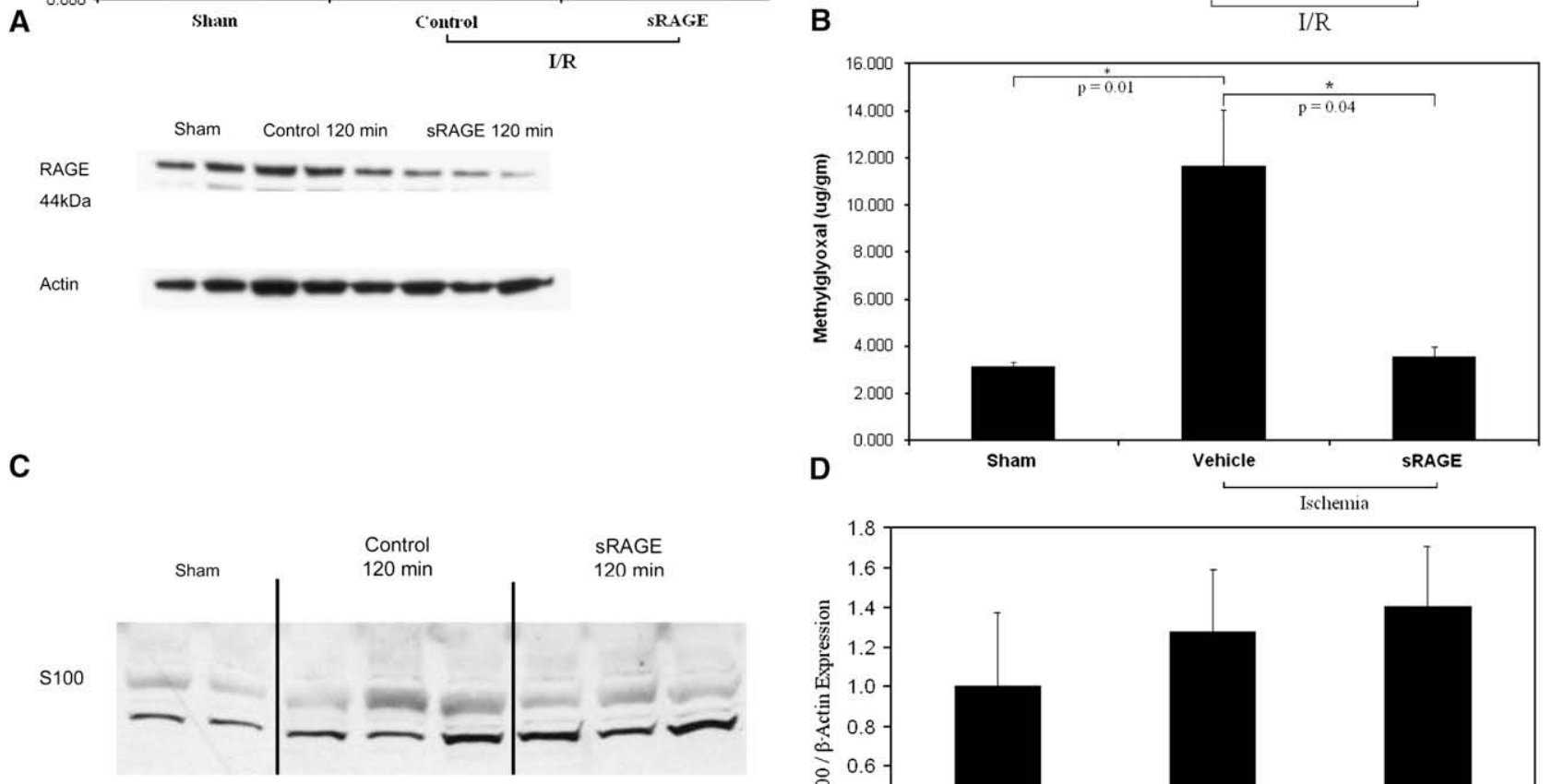

Actin

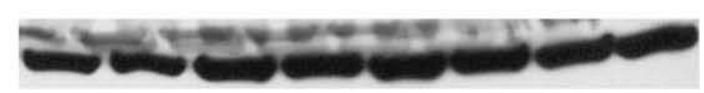

E
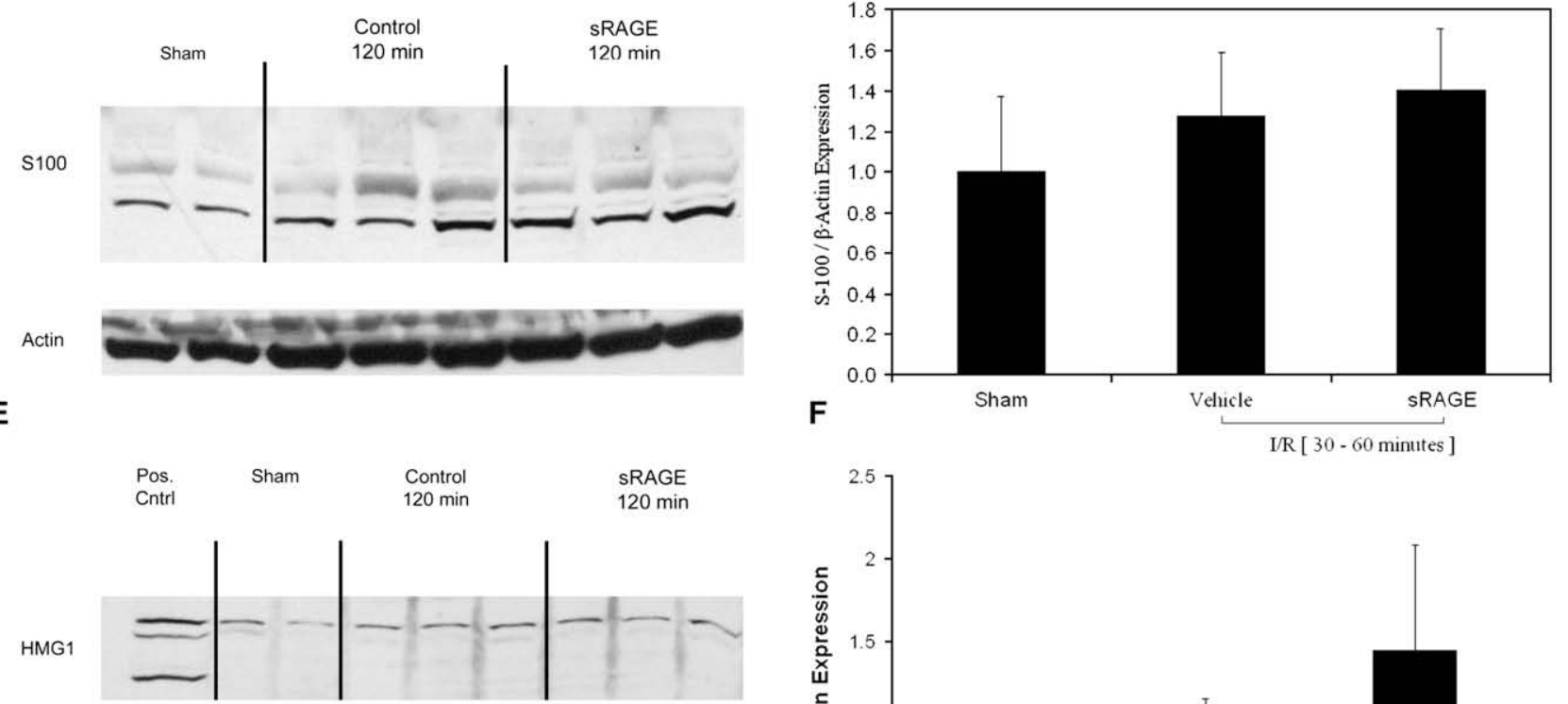

Actin

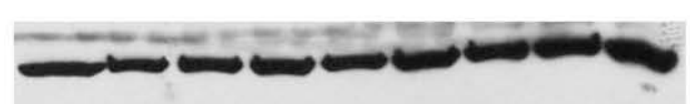

G

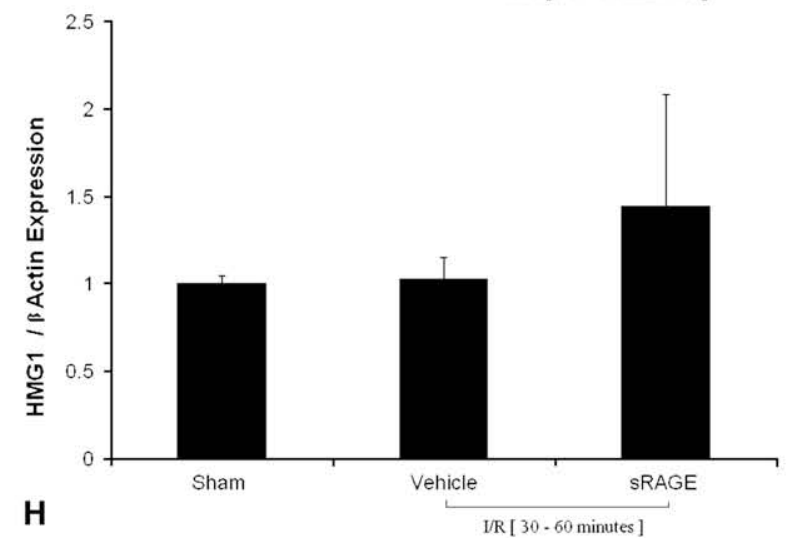


approximately $137 \pm 5 \mathrm{~mm} \mathrm{Hg}$. After 30 minutes of ischemia and 60 minutes of reperfusion, the $\mathrm{PO}_{2}$ in vehicle-treated animals ( $73 \pm 8 \mathrm{~mm} \mathrm{Hg}$ ) was significantly lower than that seen in sRAGE-treated animals $(108 \pm 9 \mathrm{~mm} \mathrm{Hg}, P=$ $.0094)$ or RAGE-null mice $(109 \pm 7 \mathrm{~mm} \mathrm{Hg}, P=.003$; Figure $2, A$ ). Oxygenation was also evaluated after 30 minutes of ischemia, with reperfusion extended to 120 minutes. The $\mathrm{PO}_{2}$ in vehicle-treated animals after 120 minutes $(66 \pm 9 \mathrm{~mm}$ $\mathrm{Hg}$ ) was significantly lower than that seen in sRAGE-treated mice (94 $\pm 8 \mathrm{~mm} \mathrm{Hg}, P=.003$; Figure 2, $B$ ). Furthermore, we extended ischemia to 60 minutes and reperfusion to 120 minutes and remeasured oxygenation. Vehicle-treated animals exhibited a lower mean $\mathrm{PO}_{2}(56 \pm 6 \mathrm{~mm} \mathrm{Hg})$ compared with sRAGE-treated animals $(102 \pm 8 \mathrm{~mm} \mathrm{Hg}, P=.0001)$. The blood gases for each experimental group are shown in Table 1. Significant differences were only observed for $\mathrm{PO}_{2}$ and oxygen saturation but not for $\mathrm{pH}, \mathrm{PCO}_{2}$, or $\mathrm{HCO} 3$ levels.

Pathologic analyses have established vascular permeability as a central characteristic finding of acute lung injury. We evaluated the protein permeability of the respiratory membrane by injecting fluorescein-labeled albumin into the tail vein before surgical intervention and then measuring the fluorescent intensity of alveolar lavage fluid normalized to serum (Figure 2, C). After 30 minutes of ischemia and 60 minutes of reperfusion, alveolar lavage fluorescent intensity was approximately 6.1-fold higher in vehicle-treated animals but only approximately 1.7 -fold higher in sRAGEtreated animals compared with that seen in mice subjected to sham operations $(P<.001)$. Measurement of lavage fluorescent intensity after 30 minutes of ischemia and $120 \mathrm{~min}$ utes of reperfusion demonstrated significantly higher levels in vehicle-treated animals (approximately 4.9-fold) than seen in sRAGE-treated animals (approximately 1.9-fold, $P=.03$ ) or RAGE-null mice (approximately 1.5 -fold, $P=$ .02 ; Figure 2, $D$ ).

\section{Histology}

Hematoxylin and eosin-prepared specimens were prepared from murine lungs after 60 minutes of ischemia and 120 minutes of reperfusion (Figure 3, A). Each specimen was scored from 0 (no injury) to 4 (most severe injury) on each of 4 axes, as described above. Vehicle-treated animals demonstrated significantly greater histologic injury (mean score, 6.3) versus that seen in sRAGE-treated animals (mean score, $4.8 ; P=.01$ ), RAGE-null animals (mean score, $5.2 ; P=.03$ ), or sham-treated animals (mean score, $4.5 ; P=$ .007 ). Figure $3, B$ and $C$, shows representative sections from
sRAGE- and vehicle saline-treated mice after 60 minutes of ischemia and 120 minutes of reperfusion.

\section{Interleukin 8 and $\mathrm{KC}$ protein}

Interleukin 8 , a proinflammatory cytokine with a profound chemotactic effect on neutrophils, is a marker of pulmonary reperfusion injury. ${ }^{32}$ Increased posttransplantation levels of interleukin 8 correlate well with poor oxygenation, increased airway pressures, decreased APACHE scores, and decreased patient survival. ${ }^{32}$ We therefore measured interleukin 8 , transcripts as well the murine protein homolog of interleukin $8, \mathrm{KC}$ protein, in our model of reperfusion injury with and without sRAGE antagonism (Figure 4). ${ }^{33,34}$ After 30 minutes of ischemia and 60 minutes of reperfusion, vehicletreated animals displayed approximately 31.5 times higher interleukin 8 transcripts than sham-treated animals. In contrast, sRAGE-treated animals exhibited only a 13.8 -fold increase $(P=.02)$. Analysis of $\mathrm{KC}$ protein content by means of ELISA in lung homogenates demonstrated a statistically significant increase in vehicle-treated animals $(444.5 \mathrm{pg} /$ $\mathrm{mL}$ ) compared with that seen in sRAGE-treated mice $(171.5 \mathrm{pg} / \mathrm{mL}, P=.02)$ or sham-treated animals $(43.7 \mathrm{pg} /$ $\mathrm{mL}, P=.008)$.

\section{$\mathbf{N F}-\kappa \mathrm{B}$}

NF- $\kappa \mathrm{B}$ is a ubiquitous transcription factor that is activated by a large variety of stimuli, including hypoxia and ischemia. When activated, subunits of NF- $\kappa \mathrm{B}$ relocate into the nucleus and upregulate a variety of genes that together coordinate the inflammatory response. ${ }^{35}$ Previous studies revealed that inhibition of NF- $\kappa \mathrm{B}$ activation and nuclear localization have been shown to attenuate the severity of pulmonary reperfusion injury in a porcine model. ${ }^{36}$ Thus to discern the potential effect of RAGE on NF- $\kappa$ B activation in this murine model, we measured activated NF- $\kappa \mathrm{B}$ in nuclear preparations of lung homogenates after 30 minutes of ischemia and 60 minutes of reperfusion. An increase in activated $\mathrm{NF}-\kappa \mathrm{B}$ levels was observed in vehicle-treated animals compared with that seen in the sRAGE-treated $(P=.004)$ or sham-treated $(P=.01)$ groups (Figure 5).

\section{DISCUSSION}

In human subjects PGD is characterized by endothelial dysfunction, loss of the alveolar boundary, and leukocytic infiltration. ${ }^{20,37,38}$ Strong evidence suggests the inciting event for this process occurs during pulmonary reperfusion. ${ }^{3,7-12}$ An activated and dysfunctional pulmonary endothelial surface promotes platelet margination, sequestration,

FIGURE 1. Left lung tissue was retrieved at the indicated time points and prepared for analyses. A, Real-time polymerase chain reaction analysis of receptor for advanced glycation end products $(R A G E)$ transcript after reperfusion injury $(\mathrm{n}=8)$. B and C, Western blot analysis of RAGE protein after ischemia and reperfusion $(\mathrm{n}=9)$. D, Methylglyoxal concentration after 30 minutes of ischemia $(\mathrm{n}=5)$. E and F, Western blot analysis of S100 $(\mathrm{n}=6, P>.5)$. $\mathrm{G}$ and $\mathrm{H}$, Western blot analysis of high-mobility group box-1 (HMG1; $\mathrm{n}=6, P>.5)$. $s R A G E$, Soluble receptor for advanced glycation end products; $I / R$, ischemia and reperfusion injury. 

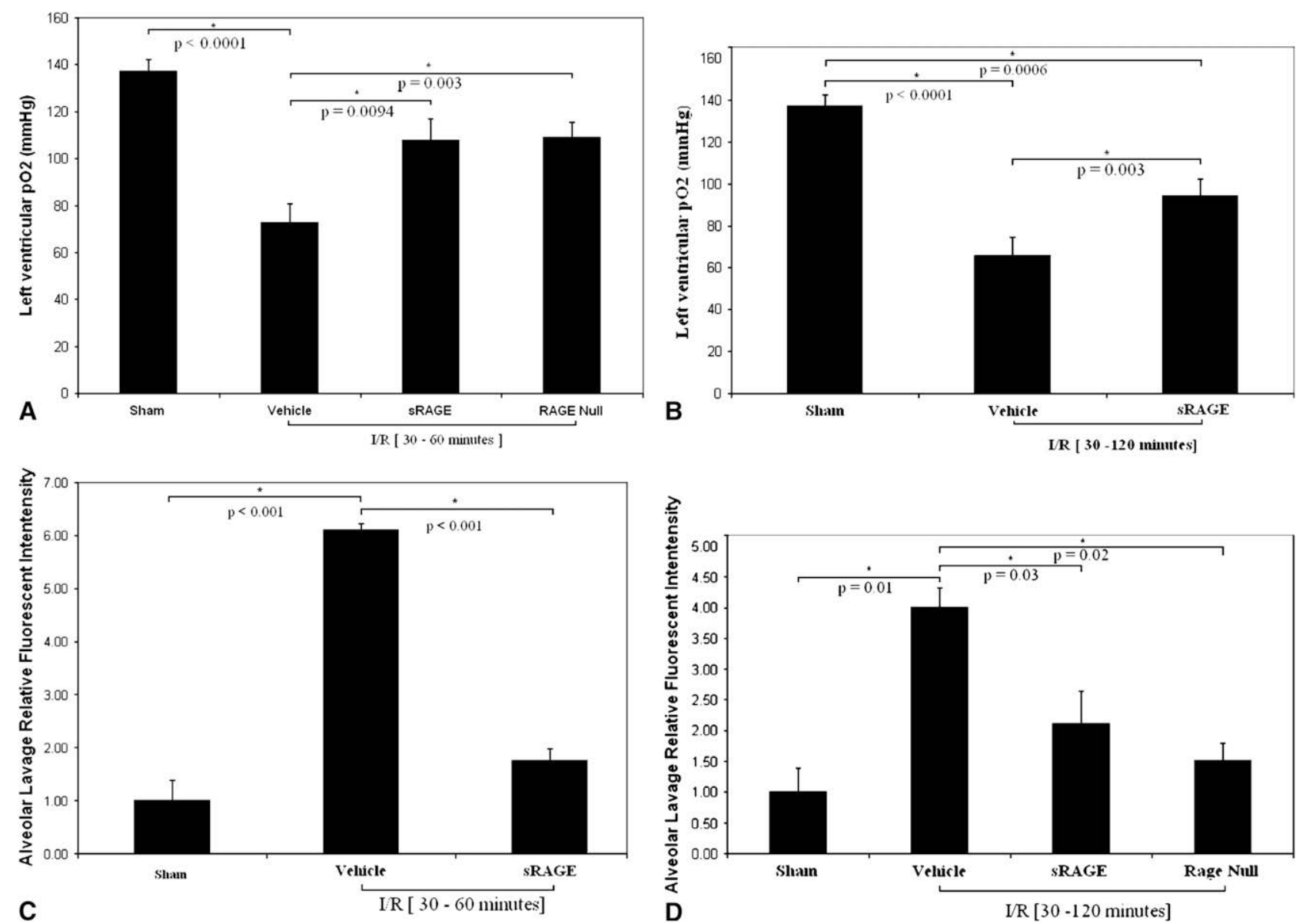

FIGURE 2. Analyses of pulmonary function. A and B, Oxygenation is measured after reperfusion by means of blood gas analysis at 2 time points: 60 minutes $(\mathrm{n}=13)$ and 120 minutes $(\mathrm{n}=17)$. C and $\mathrm{D}$, Capillary leak data were measured after 60 minutes $(\mathrm{n}=7)$ and 120 minutes of reperfusion $(\mathrm{n}=7)$. RAGE, Receptor for advanced glycation end products; $s R A G E$, soluble receptor for advanced glycation end products; $I / R$, ischemia and reperfusion injury.

and stimulation of complement activation, thus exacerbating local tissue injury caused by hypoxia, cold storage, and later reactive oxygen metabolites. ${ }^{39-44}$ Recruited neutrophils release TNF- $\alpha$, as well as other chemokines, and contribute to a more sustained injury that is thought to peak several hours after reperfusion commences. ${ }^{45,46} \mathrm{~A}$ local proinflammatory state, similar to that of acute respiratory distress syn-

TABLE 1. Arterial Blood Gas Analysis

\begin{tabular}{|c|c|c|c|c|c|}
\hline & pH & $\mathrm{PCO}_{2}$ & $\mathrm{PO}_{2}$ & $\mathrm{HCO3}^{-}$ & $\begin{array}{c}\text { Oxygen } \\
\text { saturation }\end{array}$ \\
\hline Sham & $7.35 \pm 0.03$ & $28.3 \pm 3.1$ & $137 \pm 5$ & $14.5 \pm 0.8$ & $99 \pm 0.1$ \\
\hline $\begin{array}{l}\text { Vehicle } \\
\text { saline }\end{array}$ & $7.32 \pm 0.03$ & $31.4 \pm 4.0$ & $73 \pm 8$ & $15.4 \pm 1.0$ & $90 \pm 3$ \\
\hline $\begin{array}{l}\text { sRAGE } \\
\text { treated }\end{array}$ & $7.30 \pm 0.02$ & $30.7 \pm 2.3$ & $108 \pm 9$ & $15 \pm 0.6$ & $96 \pm 1.5$ \\
\hline RAGE null & $7.34 \pm 0.03$ & $25.2 \pm 3.4$ & $109 \pm 7$ & $14.5 \pm 1.1$ & $96 \pm 1.1$ \\
\hline$P$ value & .65 & .53 & $<.001$ & .86 & .03 \\
\hline
\end{tabular}

drome, is achieved that causes type 1 alveolar epithelial cell dysfunction and results in diminished alveolar space fluid clearance. ${ }^{20}$

RAGE is both a marker of type I alveolar epithelial cell injury and a key early regulator of inflammation. ${ }^{13-15}$ RAGE is a multiligand, immunoglobulin-type transmembrane receptor that is widely expressed on endothelial and inflammatory cell surfaces and at particularly high concentrations on the basolateral surface of type 1 alveolar cells. ${ }^{16-19}$ RAGE plays a critical role in inflammatory cascades that lead to endothelial dysfunction and capillary permeability. The first RAGE ligand families include AGEs, the products of nonenzymatic glycation and oxidation of proteins that accumulate during diabetes, aging, renal failure, oxidative stress, and neurodegeneration. RAGE was also found to be a signal transduction receptor for S100/calgranulins and HMGB1 ligands, which are proinflammatory cytokines secreted by activated macrophages. ${ }^{29,31,47,48}$ RAGE-ligand interaction can stimulate diverse signaling 

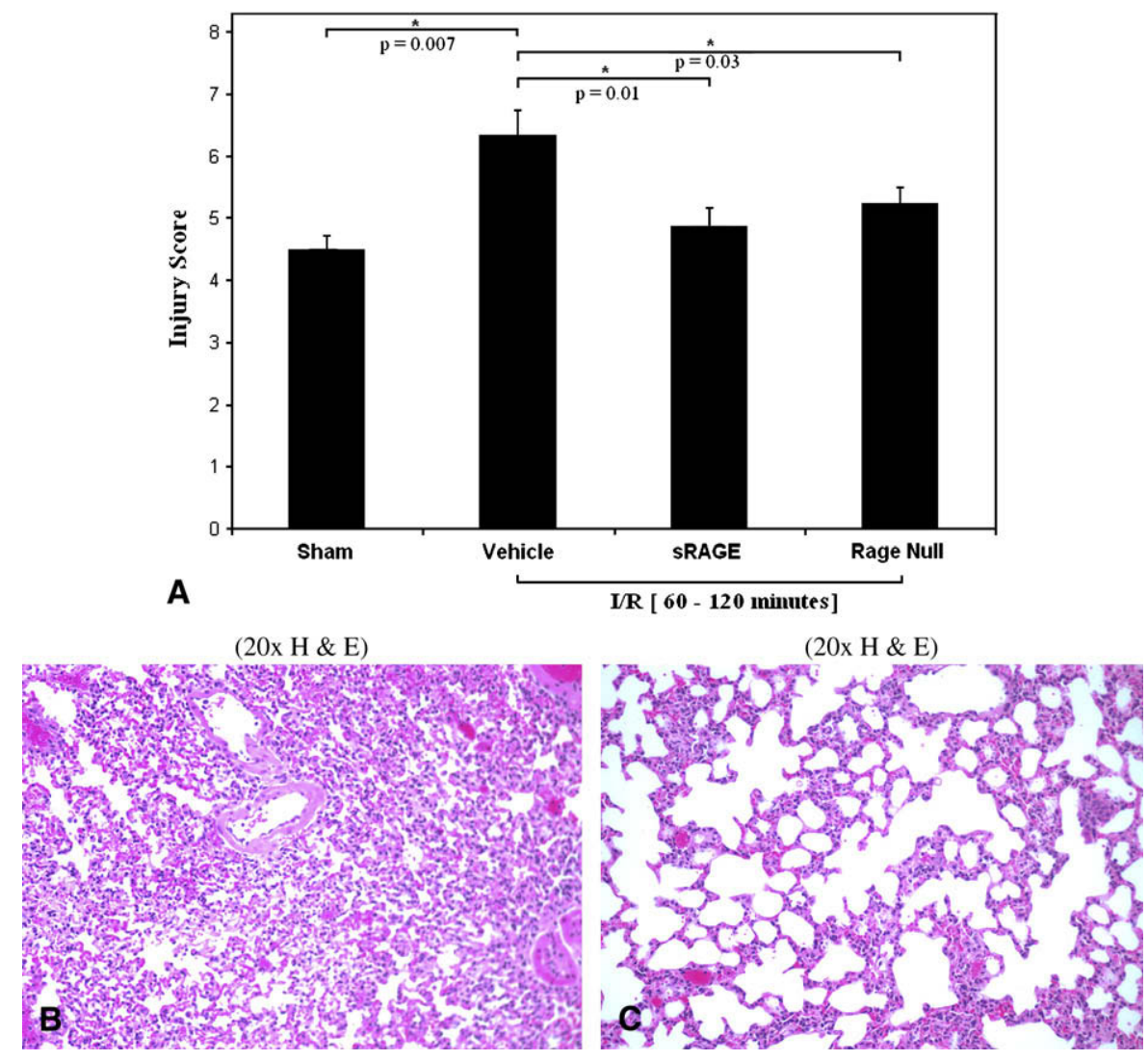

FIGURE 3. Severity of histologic injury is scored by a pathologist naive to the experimental conditions on a scale from 0 (no injury) to 4 (most severe injury) along 4 categories (capillary congestion, hemorrhage, edema, and inflammation) after 60 minutes of ischemia and 120 minutes of reperfusion. Scores were then summed for each animal $(\mathrm{n}=8)$. B and $\mathrm{C}$, Representative hematoxylin and eosin $(H \& E$; original magnification $20 \times)$ stain of vehicle saline-treated (B) and soluble receptor for advanced glycation end products ( $S R A G E)$-treated $(C)$ lung demonstrating increased edema and inflammatory response after 60 minutes of ischemia and 120 minutes of reperfusion. $I / R$, Ischemia and reperfusion injury.

pathways, such as Janus kinase/signal transducer and activator of transcription, p44/p42, p38, SAP/c-Jun N-terminal kinase, and mitogen-activated protein kinases, and yield nuclear localization of NF- $\kappa \mathrm{B}$ and thereby proinflammatory phenotypes. ${ }^{49-52}$

In this article we have shown that pharmacologic antagonism or genetic deletion of RAGE attenuates pulmonary reperfusion injury in a murine model. We have shown that oxygenation, capillary leakage, and histologic injury all improved in animals pretreated with the RAGE ligand decoy sRAGE. RAGE was a critical target of ligand-mediated injury because RAGE-null mice also did not have pulmonary reperfusion injury. Previous reports have suggested RAGE involvement in IR because lavage and serum levels of sRAGE were increased in this setting and because concentration correlated with clinical outcome. However, to our knowledge, this is the first report that functional blockade of the RAGE axis attenuates or prevents reperfusion injury, thus establishing the RAGE pathway as important in the development of reperfusion injury.

We also studied the biology of the RAGE axis in a murine model of reperfusion injury. We were surprised to discover decreased quantities of RAGE transcript and protein because RAGE is typically upregulated at sites of chronic inflammatory injury. ${ }^{53}$ However, these findings might highlight specific and unique aspects of the biology of RAGE in the lung. For example, RAGE is normally expressed at low levels in most organs and upregulated during inflammatory injury. In the lung, in contrast, baseline RAGE expression increases with age from birth to high levels in adulthood and might be downregulated in response to certain specific stimuli. ${ }^{17,54,55}$ For example, exposure to hyperoxic atmospheres causes downregulation of pulmonary RAGE in the rat. ${ }^{55}$ Additionally downregulation of RAGE protein supports the growth and metastasis of pulmonary carcinoma. ${ }^{56}$ Other reports, however, suggest upregulation of RAGE might occur in response to inflammatory stimuli in the lung, such as exposure to cigarette smoke or chronic pneumonia. ${ }^{57}$ One possibility is that these diverse injuries cause severe damage and/or loss of the RAGE-expressing type 1 alveolar epithelial cells. Alternatively, these injuries might stimulate diverse changes in gene expression in these cells, including downregulation of RAGE. Because the reports all use different models of lung injury (eg, cigarette smoke, 

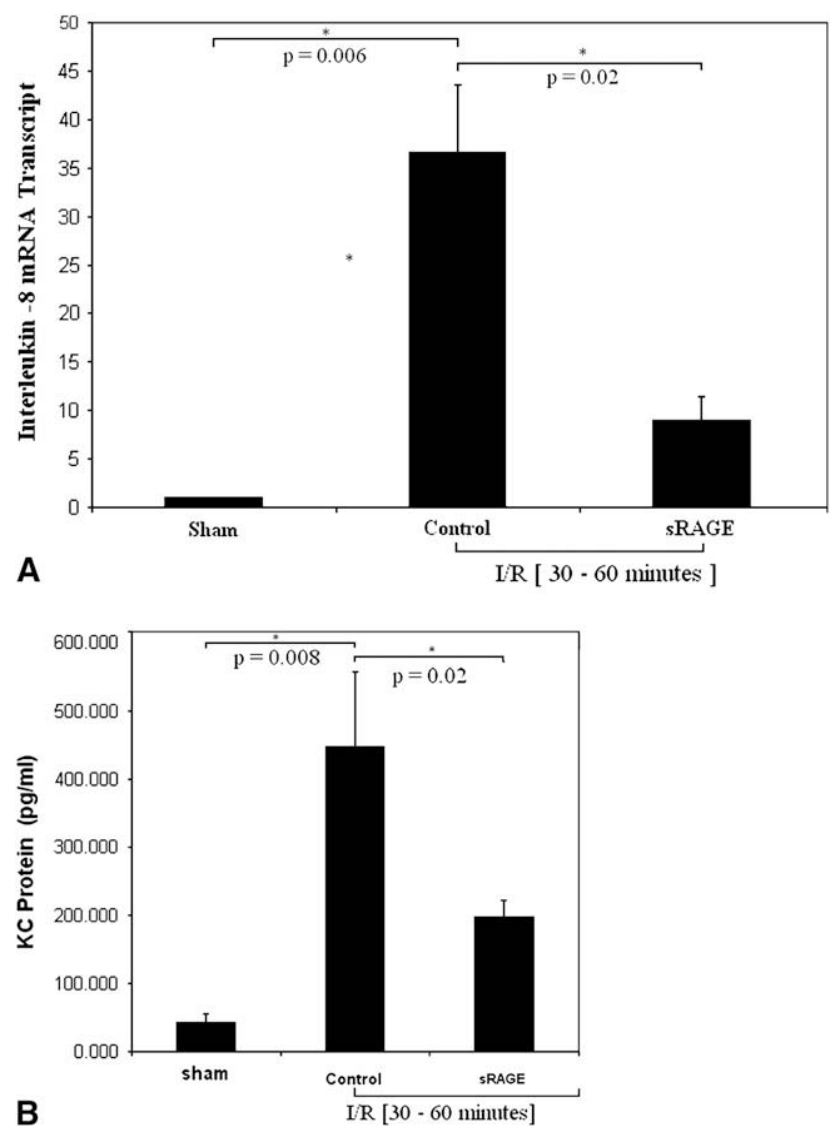

FIGURE 4. Left lung tissue was retrieved at the indicated time points and prepared for analyses. A, Real-time polymerase chain reaction analysis of interleukin 8 transcript after 30 minutes of ischemia and 60 minutes of reperfusion $(\mathrm{n}=9)$. B, Enzyme-linked immunosorbent assay detection of $\mathrm{KC}$ protein (interleukin 8 murine homologue) after 30 minutes of ischemia and 60 minutes of reperfusion $(\mathrm{n}=10)$. $s R A G E$, Soluble receptor for advanced glycation end products; $I / R$, ischemia and reperfusion injury.

endotoxin, acid, and hypoxia), generalization of the RAGE protein regulation during pulmonary injury might not be possible at this time. Scrutiny of the concentration of SRAGE in various disease states has also not been consistent to date. ${ }^{58} \mathrm{~A}$ variety of reports document increases in sRAGE concentrations in diabetic vasculopathy, chronic kidney disease, and acid-injured lungs. ${ }^{13,59,60}$ Other reports, however, suggest a decreased concentration of sRAGE in hypertension, Alzheimer's disease, and coronary artery disease. ${ }^{61-63}$ Because the disease states and respective mechanisms vary significantly, it is perhaps too early to draw clear conclusions. Clearly, the biology of the RAGE axis in the lung is complex and warrants further investigation.

MG is a highly reactive metabolite that is formed by conditions created by high oxidative stress and catalyzes the formation of AGEs. ${ }^{64}$ Although the tissue MG level is normally tightly regulated, MG concentrations increased during ischemia but rapidly normalized during reperfusion. This is con-

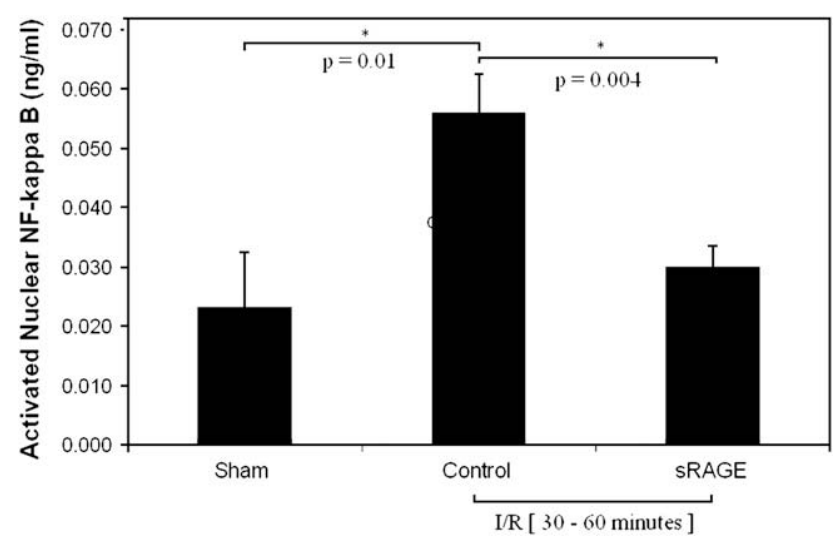

FIGURE 5. Left lung tissue was retrieved at the indicated time points and prepared for analysis of activated nuclear factor $\kappa \mathrm{B}$. Activated nuclear factor $\kappa \mathrm{B}$ measured by means of enzyme-linked immunosorbent assay in nuclear preparations after 30 minutes of ischemia and 60 of minutes reperfusion $(\mathrm{n}=11) . s R A G E$, Soluble receptor for advanced glycation end products; $I / R$, ischemia and reperfusion injury.

sistent with the highly active pulmonary glyoxalase system, which rapidly and efficiently disposes of MG, preventing fatal accumulation of this toxic compound. We also investigated 2 distinct proinflammatory RAGE ligands, HMGB1 and S100. Unlike AGEs, in this specific model we were unable to detect changes in protein levels of these RAGE ligands. However, there are a number of putative AGE ligands that might be operative during pulmonary reperfusion injury, and further work is needed to identify the specific molecule or molecules interacting with RAGE during pulmonary IR.

Interleukin 8 and NF- $\kappa \mathrm{B}$ were also studied to determine the interaction of the RAGE axis with other key modulators and markers of pulmonary IR. Increased posttransplantation levels of interleukin 8 correlate well with poor oxygenation, increased airway pressures, decreased APACHE score, and decreased patient survival. ${ }^{32}$ In our model interruption of RAGE signaling resulted in reduced interleukin 8 transcripts and its murine protein homolog, $\mathrm{KC}$, when compared with levels seen in vehicle-treated animals. Concentrations of activated NF- $\kappa \mathrm{B}$ in nuclear preparations of lung homogenate were also reduced in sRAGE-treated animals. Increases in interleukin 8 and nuclear NF- $\kappa$ B levels and histologic injury suggest that RAGE signaling precedes recruitment of the inflammatory infiltrate. This is consistent with the established role of RAGE in the early amplification of inflammatory signals.

In summary, we report that RAGE signaling blockade prevents the development of pulmonary reperfusion injury in a murine model. The high incidence and often great severity of pulmonary IR increases morbidity, limits patient survival, and limits optimal patient outcomes, severely hampering the wider application of lung transplantation in patients with end-stage respiratory failure. The absence of 
alternative, clinically viable therapeutic solutions for patients with end-stage lung disease mandates further work to elucidate the importance of RAGE signaling in human pulmonary IR.

\section{References}

1. Carter YM, Davis RD. Primary graft dysfunction in lung transplantation. Semin Respir Crit Care Med. 2006;27:501-7.

2. Trulock EP, Christie JD, Edwards LB, Boucek MM, Aurora P, Taylor DO, et al. Registry of the International Society for Heart and Lung Transplantation: twentyfourth official adult lung and heart-lung transplantation report-2007. J Heart Lung Transplant. 2007;26:782-95.

3. Christie JD, Bavaria JE, Palevsky HI, Litzky L, Blumenthal NP, Kaiser LR, et al. Primary graft failure following lung transplantation. Chest. 1998;114:51-60.

4. Christie JD, Kotloff RM, Ahya VN, Tino G, Pochettino A, Gaughan C, et al. The effect of primary graft dysfunction on survival after lung transplantation. $\mathrm{Am}$ J Respir Crit Care Med. 2005;171:1312-6.

5. Christie JD, Sager JS, Kimmel SE, Ahya VN, Gaughan C, Blumenthal NP, et al. Impact of primary graft failure on outcomes following lung transplantation. Chest. 2005; 127:161-5.

6. Whitson BA, Prekker ME, Herrington CS, Whelan TP, Radosevich DM, Hertz MI, et al. Primary graft dysfunction and long-term pulmonary function after lung transplantation. J Heart Lung Transplant. 2007;26:1004-11.

7. Wickersham NE, Johnson JJ, Meyrick BO, Gilroy RJ, Loyd JE. Lung ischemiareperfusion injury in awake sheep: protection with verapamil. J Appl Physiol. 1991;71:1554-62.

8. Thabut G, Vinatier I, Stern JB, Lesèche G, Loirat P, Fournier M, et al. Primary graft failure following lung transplantation: predictive factors of mortality. Chest. 2002;121:1876-82

9. Khan SU, Salloum J, O’Donovan PB, Mascha EJ, Mehta AC, Matthay MA, et al. Acute pulmonary edema after lung transplantation: the pulmonary reimplantation response. Chest. 1999;116:187-94.

10. Ovechkin AV, Lominadze D, Sedoris KC, Robinson TW, Tyagi SC, Roberts AM. Lung ischemia-reperfusion injury: implications of oxidative stress and platelet-arteriolar wall interactions. Arch Physiol Biochem. 2007;113:1-12.

11. Gilroy RJ Jr, Bhatte MJ, Wickersham NE, Pou NA, Loyd JE, Overholser KA. Postischemic hypoperfusion during unilateral lung reperfusion in vivo. Am Rev Respir Dis. 1993;147:276-82.

12. Miller DL, Roberts AM. Pulmonary artery occlusion and reperfusion causes microvascular constriction in the rabbit lung. Ann Thorac Surg. 1999;67:323-8.

13. Uchida T, Shirasawa M, Ware LB, Kojima K, Hata Y, Makita K, et al. Receptor for advanced glycation end-products is a marker of type I cell injury in acute lung injury. Am J Respir Crit Care Med. 2006;173:1008-15.

14. Schmidt AM, Yan SD, Yan SF, Stern DM. The multiligand receptor RAGE as a progression factor amplifying immune and inflammatory responses. J Clin Invest. 2001;108:949-55.

15. Herold K, Moser B, Chen Y, Zeng S, Yan SF, Ramasamy R, et al. Receptor for advanced glycation end products (RAGE) in a dash to the rescue: inflammatory signals gone awry in the primal response to stress. J Leukoc Biol. 2007;82:204-12.

16. Yan SF, Naka Y, Hudson BI, Herold K, Yan SD, Ramasamy R, et al. The ligand/ RAGE axis: lighting the fuse and igniting vascular stress. Curr Atheroscler Rep. 2006;8:232-9.

17. Brett J, Schmidt AM, Yan SD, Zou YS, Weidman E, Pinsky D, et al. Survey of the distribution of a newly characterized receptor for advanced glycation end products in tissues. Am J Pathol. 1993;143:1699-712.

18. Schmidt AM, Yan SD, Stern DM. The dark side of glucose. Nat Med. 1995;1: $1002-4$.

19. Ramasamy R, Yan SF, Schmidt AM. The RAGE Axis and endothelial dysfunction: maladaptive roles in the diabetic vasculature and beyond. Trends Cardiovasc Med. 2005;15:237-43.

20. Frank JA, Briot R, Lee JW, Ishizaka A, Uchida T, Matthay MA. Physiological and biochemical markers of alveolar epithelial barrier dysfunction in perfused human lungs. Am J Physiol Lung Cell Mol Physiol. 2007;293:L52-9.

21. Calfee CS, Budev MM, Matthay MA, Church G, Brady S, Uchida T, et al. Plasma receptor for advanced glycation end-products predicts duration of ICU stay and mechanical ventilation in patients after lung transplantation. J Heart Lung Transplant. 2007;26:675-80.

22. Park L, Raman KG, Lee KJ, Lu Y, Ferran LJ Jr, Chow WS, et al. Suppression of accelerated diabetic atherosclerosis by the soluble receptor for advanced glycation endproducts. Nat Med. 1998;4:1025-31.
23. Sakaguchi T, Yan SF, Yan SD, Belov D, Rong LL, Sousa M, et al. Central role of RAGE-dependent neointimal expansion in arterial restenosis. J Clin Invest. 2003; 111:959-72.

24. Ohmori S, Mori M, Kawase M, Tsuboi S. Determination of methyl-glyoxal as 2methylquinoxaline by high-performance liquid chromatography and its application to biological samples. J Chromatogr. 1987;414:149-55.

25. Bucciarelli LG, Kaneko M, Ananthakrishnan R, Harja E, Lee LK, Hwang YC, et al. Receptor for advanced-glycation end products: key modulator of myocardial ischemic injury. Circulation. 2006;113:1226-34.

26. Thornalley P. Pharmacology of methylglyoxal: formation, modification of proteins and nucleic acids, and enzymatic detoxification-A role in pathogenesis and antiproliferative chemotherapy. General Pharmacology. 1996;27:565-73.

27. Yao D, Taguchi T, Matsumura T, Pestell R, Edelstein D, Giardino I, et al. Methylglyoxal modification of mSin $3 \mathrm{~A}$ links glycolysis to angiopoietin-2 transcription. Cell. 2006;124:275-86.

28. Shinohara M, Thornalley P, Giardino I, Beisswenger P, Thorpe S, Onorato J, et al. Overexpression of glyoxalase-I in bovine endothelial cells inhibits intracellular advanced glycation endproduct formation and prevents hyperglycemia-induced increases in macromolecular endocytosis. J Clin Invest. 1998;101:1142-7.

29. Schäfer BW, Heizmann CW. The S100 family of EF-hand calcium-binding proteins: functions and pathology. Trends Biochem Sci. 1996;21:134-40.

30. Wittkowski H, Sturrock A, van Zoelen MA, Viemann D, van der Poll T, Hoidal JR, et al. Neutrophil-derived S100A12 in acute lung injury and respiratory distress syndrome. Crit Care Med. 2007;35:1369-75.

31. Wang H, Bloom O, Zhang M, Vishnubhakat JM, Ombrellino M, Che J, et al. HMG-1 as a late mediator of endotoxin lethality in mice. Science. 1999;285: 248-51.

32. De Perrot M, Sekine Y, Fischer S, Waddell TK, McRae K, Liu M, et al. Interleukin-8 release during early reperfusion predicts graft function in human lung transplantation. Am J Respir Crit Care Med. 2002;165:211-5.

33. Watanabe K, Konishi K, Fujioka M, Kinoshita S, Nakagawa H. The neutrophil chemoattractant produced by the rat kidney epithelioid cell line NRK-52E is a protein related to the KC/gro protein. J Biol Chem. 1989;264:19559-63.

34. Van Damme J, Wuyts A, Froyen G, Van Coillie E, Struyf S, Billiau A, et al. Granulocyte chemotactic protein-2 and related CXC chemokines: from gene regulation to receptor usage. J Leukoc Biol. 1997;62:563-9.

35. Gilmore TD. Introduction to NF-kappaB: players, pathways, perspectives. Oncogene. 2006;25:6680-4.

36. Ross SD, Kron IL, Gangemi JJ, Shockey KS, Stoler M, Kern JA, et al. Attenuation of lung reperfusion injury after transplantation using an inhibitor of nuclear factorkappaB. Am J Physiol Lung Cell Mol Physiol. 2000;279:L528-36.

37. Ng CS, Wan S, Arifi AA, Yim AP. Inflammatory response to pulmonary ischemia-reperfusion injury. Surg Today. 2006;36:205-14.

38. Naka Y, Chowdhury NC, Oz MC, Smith CR, Yano OJ, Michler RE, et al. Nitroglycerin maintains graft vascular homeostasis and enhances preservation in an orthotopic rat lung transplant model. J Thorac Cardiovasc Surg. 1995;109:206-10.

39. Ogawa S Shreeniwas R, Brett J, Clauss M, Furie M, Stern DM. The effect of hypoxia on capillary endothelial cell function: modulation of barrier and coagulant function. Br J Haematol. 1990;75:517-24.

40. Colombat M, Castier Y, Leseche G, Rufat P, Mal H, Thabut G, et al. Early expression of adhesion molecules after lung transplantation: evidence for a role of aggregated P-selectin-positive platelets in human primary graft failure. J Heart Lung Transplant. 2004;23:1087-92.

41. Patel KD Zimmerman GA, Prescott SM, McEver RP, McIntyre TM. Oxygen radicals induce human endothelial cells to express GMP-140 and bind neutrophils. $J$ Cell Biol. 1991;112:749-59.

42. Ogawa S, Koga S, Kuwabara S, Brett J, Morrow B, Morris SA, et al. Hypoxia induced increased permeability of endothelial monolayers occurs through lowering of cAMP levels. Am J Physiol. 1992;262:546-54.

43. Naka Y, Hirose H, Matsuda H, Shirakura R, Miyagawa S, Fukushima N, et al. Prevention of pulmonary edema developing in autoperfusing heart-lung preparation by leukocyte depletion. Eur J Cardiothorac Surg. 1989;3:355-8.

44. Levine AJ, Parkes K, Rooney S, Bonser RS. Reduction of endothelial injury after hypothermic lung preservation by initial leukocyte-depleted reperfusion. J Thorac Cardiovasc Surg. 2000;120:47-54.

45. Eppinger MJ, Deeb GM, Bolling SF, Ward PA. Mediators of ischemia-reperfusion injury of rat lung. Am J Pathol. 1997;150:1773-84.

46. Fujita T, Asai T, Andrassy M, Stern DM, Pinsky DJ, Zou YS, et al. PKCbeta regulates ischemia/reperfusion injury in the lung. J Clin Invest. 2004;113:1615-23.

47. Andersson U, Wang H, Palmblad K, Aveberger AC, Bloom O, ErlandssonHarris $\mathrm{H}$, et al. High mobility group 1 protein (HMG-1) stimulates 
proinflammatory cytokine synthesis in human monocytes. J Exp Med. 2000; 192:565-70.

48. Donato R. S100: a multigenic family of calcium-modulated proteins of the EFhand type with intracellular and extracellular functional roles. Int $J$ Biochem Cell Biol. 2001;33:637-68.

49. Lander HM, Tauras JM, Ogiste JS, Hori O, Moss RA, Schmidt AM. Activation of the receptor for advanced glycation end products triggers a p21(ras)-dependent mitogen-activated protein kinase pathway regulated by oxidant stress. $J$ Biol Chem. 1997;272:17810-4.

50. Huang JS, Guh JY, Chen HC, Hung WC, Lai YH, Chuang LY. Role of receptor for advanced glycation end-product (RAGE) and the JAK/STAT-signaling pathway in AGE-induced collagen production in NRK-49F cells. J Cell Biochem. 2001;81:102-13.

51. Bierhaus A, Schiekofer S, Schwaninger M, Andrassy M, Humpert PM, Chen J, et al. Diabetes-associated sustained activation of the transcription factor nuclear factor-kappaB. Diabetes. 2001;50:2792-808.

52. Barnes PJ, Karin M. Nuclear factor-kappaB: a pivotal transcription factor in chronic inflammatory diseases. N Engl J Med. 1997;336:1066-71.

53. Goldin A, Beckman JA, Schmidt AM, Creager MA. Advanced glycation end products: sparking the development of diabetic vascular injury. Circulation. 2006;114:597-605.

54. Hanford LE, Fattman CL, Shaefer LM, Enghild JJ, Valnickova Z, Oury TD. Regulation of receptor for advanced glycation end products during bleomycin-induced lung injury. Am J Respir Cell Mol Biol. 2003;29(suppl):S77-81.

55. Lizotte PP, Hanford LE, Enghild JJ, Nozik-Grayck E, Giles BL, Oury TD. Developmental expression of the receptor for advanced glycation end-products (RAGE) and its response to hyperoxia in the neonatal rat lung. BMC Dev Biol. 2007;7:15.
56. Bartling B, Hofmann HS, Weigle B, Silber RE, Simm A. Down-regulation of the receptor for advanced glycation end-products (RAGE) supports non-small cell lung carcinoma. Carcinogenesis. 2005;26:293-301.

57. Morbini P, Villa C, Campo I, Zorzetto M, Inghilleri S, Luisetti M. The receptor for advanced glycation end products and its ligands: a new inflammatory pathway in lung disease? Mod Pathol. 2006;19:1437-45.

58. Koyama H, Yamamoto H, Nishizawa Y. RAGE and soluble RAGE: potential therapeutic targets for cardiovascular diseases. Mol Med. 2007;13:625-35.

59. Tan KC, Shiu SW, Chow WS, Leng L, Bucala R, Betteridge DJ. Association between serum levels of soluble receptor for advanced glycation end products and circulating advanced glycation end products in type 2 diabetes. Diabetologia. 2006;49:2756-62.

60. Humpert PM, Djuric Z, Kopf S, Rudofsky G, Morcos M, Nawroth PP, et al. Soluble RAGE but not endogenous secretory RAGE is associated with albuminuria in patients with type 2 diabetes. Cardiovasc Diabetol. 2007;7:9.

61. Geroldi D, Falcone C, Minoretti P, Emanuele E, Arra M, D'Angelo A. High levels of soluble receptor for advanced glycation end products may be a marker of extreme longevity in humans. J Am Geriatr Soc. 2006;54:1149-50.

62. Emanuele E, D'Angelo A, Tomaino C, Binetti G, Ghidoni R, Politi P, et al. Circulating levels of soluble receptor for advanced glycation end products in Alzheimer disease and vascular dementia. Arch Neurol. 2005;62:1734-6.

63. Geroldi D, Falcone C, Emanuele E, D’Angelo A, Calcagnino M, Buzzi MP, et al. Decreased plasma levels of soluble receptor for advanced glycation end-products in patients with essential hypertension. J Hypertens. 2005;23:1725-9.

64. Thornalley PJ. The glyoxalase system: new developments towards functional characterization of a metabolic pathway fundamental to biological life. Biochem J. 1990;269:1-11. 